\title{
A CRITICAL ASSESSMENT OF THE CONSTRUCT OF ATTITUDE IN SOCIOLINGUISTICS: A SOCIO-PSYCHOLOGICAL INSIGHT (PART 2)
}

Keywords: sociolinguistics, language attitude, attitude-behaviour relations, the theory of
planned behaviour

\begin{abstract}
The present article constitutes the second part of a brief critical analysis of the research on attitude and attitude-(speech) behaviour relations. Its major aim is to show that the contribution from the socio-psychological paradigm can prove relevant and valuable when applied to sociolinguistic research on attitude and attitude-behaviour relations. The author argues that attitudinal investigations in sociolinguistics, despite their popularity and rich history, frequently suffer from a number of methodological and theoretical flaws. The author advances an argument that a reconceptualization of the construct of attitude and some additional methodological principles can help refine the whole paradigm of language attitude research. Specifically, it is pointed out that a cognitive/information-processing approach to attitude formation, the theory of planned behaviour and other theoretical and methodological insights discussed in this paper can prove immensely rewarding and can give a new impetus for further research.
\end{abstract}

\section{Attitude - conceptual issues}

It seems worth starting a discussion of the conceptualization of attitude by pointing to one of the most fundamental distinctions to be made in the social sciences and humanities, i.e. the one between behaviourist and mentalist approaches. This will also provide a broader perspective on the language attitude paradigm. In this vein, 
as Fasold $(1984: 147,148)$ elucidates, behaviourists tend to presume that attitudes can be derived from people's responses to social situations and that it is not necessary to rely on respondents' self-reports or indirect inferences since it is enough for the researcher to focus on the overt behaviour itself. Supporters of the latter approach, in turn, consider attitudes to be internal states of readiness or "an intervening variable between a stimulus affecting a person and that person's response" (Fasold 1984: 147). The mentalist conception of attitudes poses some methodological difficulties related to their measurement as internal states are not conducive to direct observation. In this vein, Liebscher and Dailey-O'Cain (2017: 2) point out that attitudes are mental entities and, as such, they remain largely inaccessible if people do not express them. Drawing on socio-psychological models from the 1950s, many language scholars adopted a tripartite conceptualizations of language attitudes (cf. Giles, Marlow 2011: 163) in which they are conceived of as structures comprising thoughts, feelings and behaviours. Accordingly, it seems that one would be justified to argue that models of this type might, in fact, be considered to try to combine design elements of both mentalist and behaviourist approaches, which as the history of research on attitude-behaviour relations appears to indicate - has proved to be in many cases a major setback to understanding the role of attitude in explaining and predicting human conduct.

Language attitudes research in sociolinguistics has clearly had its ups and downs. Interestingly, the majority of the latter seem to be traceable to the issue of the conceptualization of attitude. Much indicates that in order to fully comprehend and effectively investigate the role of attitude in human conduct, it is necessary in the first place to give careful thought to both theoretical and methodological matters. An additional problem is that language attitudes research has become an umbrella term under which numerous investigations are pursued which concern, in fact, some other related concepts; for instance, beliefs, opinions, stereotypes, ideologies or prejudices. Accordingly, the major flaw of numerous studies is that they do not examine attitude with affect/evaluation as its most important characteristic feature but simply chart beliefs that people hold about an attitude object. This has come to be referred to as an affective vacuum. In this vein, Cargile and Giles (1997: 195) argue that although it is common knowledge that attitude includes both cognitively-based reactions and feelings towards the attitude object, this affective dimension has been blatantly disregarded. In view of this, a host of social psychologists of language have arrived at a conclusion that numerous investigations claiming to be attitudinal studies focus, as a matter of fact, only on beliefs and that examination of attitude would require probing also into the affective dimension (Edwards 1999: 109).

Nota bene, social psychologists also faced similar problems in the 1960 s and 1970 . In fact, it is argued that the field of social psychology was in considerable disarray in this respect since the concept of attitude tended to be used interchangeably with such notions as stereotypes, prejudice, ethnocentrism, intentions and beliefs (Fishbein, Ajzen 1975: 1). Because of this lack of conformity in the conceptualization, a large number of methods measuring attitude were developed. This led to the further 
weakening of its explanatory and predictive power as well as to mounting criticism directed against it by a host of social psychologists (see Fishbein, Ajzen 1975: 1-2). Consequently, a recent renewal of interest in language attitudes and attempts to critically reexamine the field are likely to benefit considerably from an analysis of the socio-psychological research on attitudes. In this context, the insight offered by the theoretical framework developed by Martin Fishbein and Icek Ajzen seems particularly relevant and valuable, especially thanks to its conceptual clarity and statistically proven effectiveness. As mentioned, it is rather impossible to examine the role of attitude in determining behaviour without first establishing the conceptual relations between behaviour and beliefs, attitudes and intentions (traditionally regarded as cognitive, affective and conative components of the single construct "attitude"). As early as in the 1970s Fishbein and Ajzen (1975) started to popularize their own alternative to the tripartite model, i.e. a conceptual distinction putting belief on the cognition, and attitude on the evaluative dimension. In their newest highly influential book, the researchers continue to advocate treating cognition, evaluation and conation as three independent (though highly related) concepts, which they respectively call belief, attitude, and intention (Fishbein, Ajzen 2010). Consequently, it is maintained that opinion, knowledge, information, stereotype, etc. should be considered to belong to the category of belief; while attraction, value, valence and utility to the category of attitude (Fishbein, Ajzen 1975: 13). As regards intentions, they are thought to reflect motivational factors influencing the performance of a given behaviour and, more specifically, to reflect people's willingness and plans to expend effort to perform the behaviour in question (Ajzen 1991: 181). The stronger an individual's intention to perform a given behaviour, the more likely it is that the action will actually be carried out.

This conceptual framework is grounded in the theory of reasoned action and a cognitive/information-processing approach to attitude formation. The theory posits that "attitudes follow reasonably from the beliefs people hold about the object of the attitude, just as intentions and actions follow reasonably from attitudes" (Ajzen 1988: 32). Importantly, reasonably in this case refers to consistency and not to rationality; as critics of the approach erroneously maintain. ${ }^{1}$ To elaborate, attitudes are thought to hinge on salient (accessible) beliefs and to consist of both a relatively stable core and a more variable component (Ajzen, Sexton 1999: 134). ${ }^{2}$ They are also

Fishbein and Ajzen (2010: 398) point out that "Although we recognize that people do not necessarily act in a rational manner and that they may base their decisions on incomplete and inaccurate information, we nevertheless assume that their behavior follows reasonably, consistently, and often automatically, from the information available to them, that is, from their behavior-relevant beliefs".

2 Fishbein and Ajzen (2010: 98-99) expound that "People can, of course, form many different beliefs about an object, but we assume that only a relatively small number determine the attitude at any given moment. (...) Research suggests that people are capable of attending to or processing about five to nine items of information at a time (...). It can therefore be argued that a person's attitude toward an object is, at any given moment, primarily determined by no more than five to nine readily accessible beliefs about the object. Of course, given sufficient time and motivation, people can actively retrieve additional beliefs from memory, and these 
assumed to be subject to automatic alteration together with the emergence of new beliefs (Fishbein, Ajzen 2010: 97). A belief, in turn, refers to the information an individual has about an attitude object; specifically, it is conceptualized as subjectively perceived likelihood that a given attitude object possesses a particular attribute (Fishbein, Ajzen 2010: 96). This object-attribute link may differ from individual to individual in terms of its strength, i.e. the perceived likelihood that an object actually has a given attribute (Fishbein, Ajzen 1975: 12). The relations between beliefs and attitudes are described in greater detail by the expectancy-value model - a highly popular theoretical framework corroborated by several meta-analyses (for details, see Fishbein, Ajzen 2010: 103). The model presumes that:

[A]ttitudes develop reasonably from the beliefs people hold about the object of the attitude. Generally speaking, we form beliefs about an object by associating it with certain attributes, i.e., with other objects, characteristics, or events. [...] Since the attributes that come to be linked to the behavior are already valued positively or negatively, we automatically and simultaneously acquire an attitude toward the behavior. (Ajzen 1991: 191; cf. Fishbein, Ajzen 2010: 96)

Whether enduring or short-lived, beliefs are thought to be formed as a result of the experiences people gain throughout their lives, i.e. by means of direct observation, by accepting information from other sources (e.g. friends, relatives, the media) or through self-generation (e.g. inference processes) (Fishbein, Ajzen 2010: 96). According to the model, the beliefs held about a given attitude object need not necessarily be internally consistent since it is neither impossible nor infrequent for people to have contradictory beliefs (Fishbein, Ajzen 2010: 105).

To elaborate, attitudes are conceptualized as "a latent disposition or tendency to respond with some degree of favorableness or unfavorableness to a psychological object" (Fishbein, Ajzen 2010: 76). Latency and evaluation (specifically, the bipolar evaluative dimension of attitude) are considered to be the two features which are of greatest significance. As regards the latter, it is pointed out that most recently the majority of theorists and investigators agree that attitudes are evaluative constructs which relate an individual and his/her disposition with respect to an attitude object to a place on a scale going from positive to negative extremes (Fishbein, Ajzen 2010: 76). Latency, in turn, is thought by contemporary social and behavioural scholars to concern the association of attitude with the hypothetical disposition rather than the evaluative response itself.

Importantly, many social psychologists insist on making a systematic distinction between affect and evaluation - terms which have been traditionally used to refer to the same component of attitude. In this vein, Ajzen and Fishbein (2000: 2-3) acknowledge that to date the terms have been used interchangeably, yet, nowadays this practice may lead to some confusion at the conceptual level. Therefore, the

additional beliefs may also influence the attitude at that point in time (...). Moreover, these determinants are subject to change; additional beliefs may be formed, and existing beliefs may be strengthened, weakened, or replaced by new beliefs. Such changes would be expected to produce corresponding changes in attitudes". 
concept of affect should be reserved for situations in which it is possible to observe some kind of somatic arousal, for instance, such general mood states and emotions as sadness, happiness, anger, fear, or pride (Ajzen, Fishbein 2000: 3). Excluding affect from the conceptualization of attitude, however, is not to imply that moods and emotions have no influence on attitudes. The researchers simply argue that evaluation and affect are different concepts, but admit that the latter may have an influence on an overall evaluation, i.e. attitude. The second term - evaluation - has come to be identified with the very concept of attitude. Accordingly, attitude itself should be applied when the evaluation runs along such continua as favour - disfavour, good - bad, like - dislike, desirable - undesirable, pleasant - unpleasant (Ajzen, Fishbein 2000: 3).

\section{The principles of investigating attitudes and attitude-behaviour relations}

Dissimilar conceptualizations may well contribute to obtaining contradictory results which might lead some researchers to understate or even neglect the explanatory and predictive power of the concept of attitude. This is partly so since applying different conceptualizations of attitude has a very practical empirical dimension, i.e. it influences the kind of adjectival scales that are used in questionnaires to measure attitudes and to investigate their role in determining behaviour. Importantly, even though there are three main verbal measurement strategies applied in sociolinguistic attitudinal research, ${ }^{3}$ they seem rather unsuitable for probing into the impact of attitude on single behaviours. This is so since the evaluative measures in sociolinguistics are usually scales referring to the perceived characteristics of speakers rather than a specific behaviour itself. This remark is not meant to imply that the construction of semantic differential scales in sociolinguistics is not insightful but merely to suggest that it might be all-too-frequently inadequate when investigating attitude-speech behaviour relations. Interestingly, even Zahn and Hopper (1985: 121) warn against a decontextual and inconsiderate application of their general speech evaluation measure: "[w]e recommend that extension of speech evaluation research to new speech communities and contexts include interview and ethnographic assessment of evaluators concerns that may not be directly reflected in the items of the SEI". Obviously, this remark seems by far more relevant when SEI is applied to examine attitude-behaviour relations.

It seems that one of the most vital things that social psychologists have discovered is the differentiation between the role of attitude in determining specific behaviours as opposed to broad behavioural patterns (Ajzen, Fishbein 2005: 21-25). The immediate importance of attitude as a determinant of behaviour has come to be regarded as evident and observable mostly in behavioural aggregates. The idea

\footnotetext{
Specifically, these are the following: 1. choice of items on the basis of researchers' own interests, 2. application of general personality instruments, 3. selection of items from such tools as Speech Evaluation Instrument derived from prior empirical research (for more, see Bradac 1990: 403).
} 
behind the principle of aggregation is the assumption that any single behaviour reflects not only the influence of a relevant general disposition but also the influence of various other factors unique to the particular occasion, situation, and action being observed. By aggregating different behaviours, observed on different occasions and in different situations, these other sources of influence tend to cancel each other, with the result that the aggregate represents more valid measures of the underlying behavioural disposition than any single behaviour (Ajzen 1991: 180-181). That is why strong relations between language attitudes and single language-related behaviours may sometimes be difficult to estimate. The aggregation principle sheds light on the reasons for both lack of readily discernible correlation in a specific behaviour and its presence in behavioural aggregates.

Another vital methodological tenet, popularized by the reasoned action approach (and the theory of planned behaviour - TPB), is the principle of compatibility. Negligence in conforming to it is argued to constitute one of the major reasons for discrepancies between the assessed attitude and observable behaviour (Ajzen, Sexton 1999: 130). To elaborate, Fishbein and Ajzen expound that:

\begin{abstract}
Although we agree that attitudes are among the most important determinants of intentions and behavior, a fundamental tenet of our theoretical framework requires that the measure of attitude conform to the principle of compatibility. That is, to have predictive validity, the object of the attitude must be composed of the same target, action, context, and time elements as the behavior. Put differently, we must assess attitudes towards the very behavior that we are trying to predict and understand. (Fishbein, Ajzen 2010: 75)
\end{abstract}

Accordingly, if a researcher wants to predict respondents' performance or nonperformance of a specific behaviour, it is necessary to ask them about their attitudes towards a behaviour that is exactly at the same level of generality or specificity as the behaviour in question (Ajzen 2005: 3). In such cases, one can expect to find significant correlations between "verbal (attitudinal) and nonverbal (overt behavioural) responses" with respect to an attitude object (Ajzen, Sexton 1999: 130-131).

The principle of belief congruence constitutes one of the most essential prerequisites in the reasoned actions approach (and TPB) for investigating attitude - behaviour relations (Ajzen, Sexton 1999: 133). All in all, the belief congruence hypothesis assumes that an individual's beliefs and attitudes, despite comprising a stable core, may differ across contexts. This is so because individuals in any given situation are believed to attend only to a limited number of all the beliefs they hold about a given attitude object. Consequently, the attitudes elicited from respondents in a research situation may differ from those when individuals are on the point of deciding on a specific course of action (Ajzen 2005: 25). The activation of some particular beliefs at any given moment is attributed to specific contextual cues which are likely to differ from situation to situation. Importantly, it is argued that high belief congruence may be ensured by telling respondents to give thought to all the positive and negative sides they would weigh just before their actual performance of a certain behaviour (Ajzen, Sexton 1999: 133). It is also crucial to bear in mind the distinction 
between a simple behaviour and so called goal attainment. Whereas the former can usually be successfully anticipated thanks to an insight into one's attitude, the latter, being a complex behaviour over which individuals frequently have little volitional control, does not necessarily derive solely from attitude itself. This is so because a wide range of external factors can have a bearing on the actual success of achieving a given goal.

Finally, it seems that sociolinguistic attitudinal paradigm could also benefit (especially when focusing on attitude-behaviour relations) from placing language attitude research in the larger framework of the theory of planned behaviour (for an exemplary study, see Przygoński 2019a, 2019b ${ }^{4}$ ); a highly popular and effective model developed by socio-psychologists to anticipate and account for a wide range of human behaviours (see, for instance, Fishbein, Ajzen 2010). The logic behind it is that the framework is likely to shed fresh light not just on the actual role of language attitudes in determining a vast range of behaviours but, most of all, on evaluating their significance as compared to other two vital behavioural predictors, i.e. social pressure and perceived behavioural control. According to the theory, in order to predict the performance of a given specific behaviour, it is enough to probe into respondents' attitude together with their perceived control over a given behaviour and the social pressure (subjective norm) felt to follow a certain course of action. The actual importance of individual variables in influencing behaviour is thought to vary across contexts. The three predictors are traced to a set of behaviour-relevant beliefs (see Ajzen 2005: 9; Ajzen, Fishbein 2005: 47-48). To elaborate, a favourable attitude is formed when respondents regard the benefits deriving from a given action as more significant than its perceived drawbacks. Subjective norm, in turn, derives from normative beliefs referring to the perceived social pressure and the presumed expectations of important others to perform or not to perform a given behaviour. As for perceived behavioural control, this variable is thought to be determined by control beliefs, i.e. the factors that an individual perceives to facilitate or impede the performance of a behaviour. Importantly, the reasoned action approach, in which the theory of planned behaviour is embedded, does not address explicitly the question of the origin of behavioural, normative and control beliefs, it does, however, recognize the potential of various background factors for the formation of beliefs (Fishbein, Ajzen 2010: 24). It is maintained that various background factors may implicitly influence intentions and behaviour because of their potential influence on behavioural, normative, or control beliefs and, consequently, on attitudes, subjective norm and perceived behavioural control. ${ }^{5}$

4 The paper in question reports in detail on a study applying the theory of planned behaviour to account for students' of English motivation behind their choices of the target accent to learn as part of their university courses.

5 Fishbein and Ajzen (2010: 24-25) explain that "although a given background factor may in fact influence behavioral, normative, or control beliefs, there is no necessary connection between background factors and beliefs. Whether a given belief is or is not affected by a particular background factor is an empirical question". 


\section{Brief discussion and conclusion}

A critical assessment of the construct of attitude should not lead to its excessive criticism. However, even though the correlation between general attitudes and broad behavioural patterns seems evident for numerous scholars and laymen alike, ${ }^{6}$ there are numerous voices questioning their significance in predicting and accounting for human conduct. Moreover, even if attitudes are generally considered to be more or less stable (underlying) predispositions, there are recently some advocates of discursive and constructionist approaches perceiving attitudes to be changeable, contextual and fleeting states negotiated for the sake of achieving situational purposes which rather do not predispose in the least their holders to any systematic behavioural patterns consistent with their beliefs (cf. Liebscher, Dailey-O'Cain 2017; Soukup 2012). The insight offered by such approaches is valuable as they probe deep into the complexity and contextuality of human behaviour; yet, their epistemological positions and theoretical underpinnings appear largely to exclude any possibility of generalization and prediction. What adds to the problem in linguistics is the fact that the interrelations between language attitudes and (language) behaviour have not been explored extensively by sociolinguists and social psychologists of language. Worse still, hardly any researchers have striven to account for this apparent lack of attitude-behaviour relations by a critical examination of the conceptualization of the construct or by a thorough analysis of the methodology applied. ${ }^{7}$

In this light, it seems that the paradigm of linguistic attitudinal research is in a considerable need of its refinement and reconceptualization. Above all, the concept itself should be operationalized in accordance with the theory of planned behaviour as it would help avoid confusion in interpretation of research results, maintain conceptual clarity in research design and base the whole paradigm on strong and convincing theoretical foundations. Just as important would be a possibility of assessing the role of attitudes in influencing behaviour as compared to other two vital predictors of human action (i.e. subjective norm and perceived behavioural control). This would enable scholars to examine the role of attitudes in human conduct and would facilitate them in evaluating its relative importance in comparison to other vital determinants of human behaviour. This is more than likely to yield valuable insight conducive to letting us better comprehend the determinants of language-related behaviours and their mutual interactions across various speech communities. In addition, the theory of planned behaviour can be used not only to account for various language-related behaviours but it can also be applied to predict them or even change (language intervention) if a need arises, for instance, in educational contexts.

\footnotetext{
See the overview of literature in part 1 of this article.

7 In this vein, Ladegaard (2000: 215) makes a point that "[i]n the social-psychology of language, several studies have analyzed the affective component of a language attitude, but not many have tried to incorporate a behavioural aspect in their design".
} 
It is worth reiterating that the construct of attitude should still be considered to have a considerable explanatory (and prognostic) potential for a large number of (socio)linguistic phenomena. Nevertheless, one needs to admit that much must be done to refine and revitalize the current approach to research both on the conceptual and methodological levels. Of crucial importance is especially conceptual clarity and methodological rigour, both of which should help probe deeper into language attitudes and behaviour relations. With these points in mind and thanks to the insight offered by the theory of planned behaviour, attitudinal research can well be expected to contribute to sociolinguistic theory-building to a far greater extent. Specifically, this may be the more so if the research is conducted within the TPB framework on the following subject matter:

1. Prognostic investigations probing into the role of attitudes in more deliberate actions such as, for instance, the choice of target language (or accent) or the adoption of formal register and polite language forms during job interviews;

2. Explanatory investigations examining the role of attitudes in less deliberate and more spontaneous language-related behaviours, for example, cursing or the use of slang during conversation;

3. Applied endeavours aimed at attitude change, for instance, change of negative attitudes to language learning among adolescents or change of negative connotations attached to native neologisms.

\section{References}

Ajzen I. 1988. Attitudes, personality, and behavior. Chicago: Dorsey Press.

Ajzen I. 1991. The theory of planned behavior. - Organizational Behavior and Human Decision Processes 50: 179-211.

Ajzen I. 2005. Laws of human behavior: Symmetry, compatibility, and attitude-behavior correspondence. - Beauducel A., Biehl B., Bosniak M., Conrad W., Schönberger G., Wagener D. (eds.). 2005. Multivariate research strategies. Aachen: Shaker Verlag: 3-19.

Ajzen I., Fishbein M. 2000. Attitudes and the attitude-behavior relation: Reasoned and automatic processes. - European Review of Social Psychology 11: 1-33.

Ajzen I., Fishbein M. 2005. The influence of attitudes on behavior. - Albarracín D., Johnson B.T., Zanna M. P. (eds.). Handbook of attitudes and attitude change: Basic principles. Mahwah: Lawrence Erlbaum Associates Publishers: 1-123.

Ajzen I., Sexton J. 1999. Depth of processing, belief congruence, and attitude-behavior correspondence. - Chaiken S., Trope Y. (eds.). Dual process theories in social psychology. New York: Guilford Press: 117-138.

Bradac J. 1990. Language attitudes and impression formation. - Giles H., Robinson P. (eds.). Handbook of language and social psychology. Chichester, New York: Wiley \& Sons: $387-412$.

Cargile A.C., Giles H. 1997. Understanding language attitudes: Exploring listener affect and identity. - Language and Communication 17.3: 195-217.

Edwards J. 1999. Refining our understanding of language attitudes. - Journal of Language and Social Psychology 18.1: 101-110.

Fasold R. 1984. The sociolinguistics of society. Oxford: Blackwell. 
Fishbein M., Ajzen I. 1975. Belief, attitude, intention and behavior: An introduction to theory and research. Massachusetts: Addison-Wesley.

Fishbein M., Ajzen I. 2010. Predicting and changing behavior: The reasoned action approach. New York: Psychology Press (Taylor \& Francis).

Giles H., Marlow M.L. 2011. Theorizing language attitudes: Existing frameworks, an integrative model, and new directions. - Salmon C. (ed.). Communication yearbook 35. Thousand Oaks (CA): Sage: 161-197.

Ladegaard H.J. 2000. Language attitudes and sociolinguistic behavior: Exploring attitudebehavior relations in language. - Journal of Sociolinguistics 4.2: 214-233.

Liebscher G., Dailey-O'Cain J. 2017. Contextualizing language attitudes: An interactional perspective. - Lang Linguist Compass 2017. [https://doi.org/10.1111/Inc3.12250].

Przygoński K. 2019a. Applying the theory of planned behaviour to account for students' choice of a target accent (Part 1). - Studia Linguistica Universitatis Iagellonicae Cracoviensis 136: 169-179.

Przygoński K. 2019b. Applying the theory of planned behaviour to account for students' choice of a target accent (Part 2). - Studia Linguistica Universitatis Iagellonicae Cracoviensis 136: 199-209.

Soukup B. 2012. Current issues in the social psychological study of 'language attitudes': Constructionism, context, and the attitude-behavior link. - Language and Linguistics Compass 6.4: 212-224.

Zahn C.J., Hopper R. 1985. Measuring language attitudes: The speech evaluation instrument. - Journal of Language and Social Psychology 4.2: 113-123. 